\title{
Sustainable Supply and Demand Chain Integration within Global Manufacturing Industries
}

\author{
E. Naghi Ganji ${ }^{1}$, S. Shah ${ }^{1}$, A. Coutroubis ${ }^{1}$ \\ ${ }^{1}$ Department of Applied Engineering and Management, Faculty of Engineering and Science, University of Greenwich, \\ Chatham Maritime, Chatham, Kent, United Kingdom \\ (E.naghiganji@gre.ac.uk, S.Shah@gre.ac.uk, A.D.Coutroubis@gre.ac.uk)
}

\begin{abstract}
Given the emerging industrial management strategies considering three pillars of sustainability in particular, there is a vital need to determine the differences of sustainability practices within both supply and demand distribution systems through global manufacturing environments providing with the successful global trade and logistics. This research paper aims to explore the interactions and advantages of sustainability applications within both supply and demand chain management. The research framework adopted consists of survey questionnaire method which is conducted within a global tyre manufacturing company. The research results and analysis justify the need for the application of ethical codes, supply chain transformation and the effective association of industry executives, professional bodies and the government. The research study also identifies that the vital incentive factors for the organisation towards sustainable supply demand chain (SSDC) are mostly the financial benefits of doing so and therefore, a positive mind-set shift towards greening practices is required.
\end{abstract}

Keywords - Global manufacturing, sustainability, sustainable demand chain management (SDCM), sustainable supply chain management (SSCM), sustainable supply demand chain (SSDC).

\section{INTRODUCTION}

The triple bottom lines (TBLs) of sustainability are widely investigated within the world literature basically from environmental practices, innovative research and development (R\&D), and corporate social responsibility (CSR) to sustainable supply chain management (SSCM). From the supply and demand network point of view, several frameworks have been presented towards bridging environmental sustainable practices to the operations of different entities of the supply chain, mostly considering supplier cooperation as upstream elements for providing green raw materials. Even though, the application of sustainable practices within supply chain management from the end users' perspective and the advantages of sustainable supply and demand chain practices are still new in practice and require broader investigations especially within global manufacturing organizations. On the other hand, considering the risks associated with traditional supply chain, many authors are nowadays struggling to prove the benefits of sustainability applications within the downstream demand chain entities focusing on market mediation towards creating pull for new products [1] instead of pushing supply into the market from the traditional viewpoint of supply chain [2]. Despite the fact that "supply" is focused on reduction of uncertainty, inventory levels, bullwhip effect and lead times, supply chain management (SCM) would not necessarily be able to provide customer satisfaction [3]. The main purpose of this paper is to bridge the sustainable demand chain and supply chain along with the sustainability dimensions. The main contribution of this paper is to help companies to manage consumer demand in order to gain superior customer value.

\section{LITERATURE REVIEW}

The paper aims to examine current literature in the context of sustainability in supply and demand chain management within global manufacturing environments. The study identifies the use of sustainable practices in overall supply chain processes and presents demand chain as an alternative for integration within logistics and distribution channels within manufacturing firms.

\section{A. Sustainable Global Logistics and Supply Chain}

Sustainable production and consumption is described as "involving business, government, communities and households contributing to environmental quality through the efficient production and use of natural resources, the minimization of wastes and the optimization of products and services" [4]. However, some authors consider it an undefinable and unachievable goal which worth targeting for but does not ever reach to an actual arrival point. Hence, it is far more an ideal insight rather than a feasible possibility. Sustainable development especially within global scales necessitates deeper social justice and upgrading the people lifestyle especially in developing countries [5]. Further to the regional trade agreements such as EU and ASEAN, remarkable growth of global trade has been facilitated in recent decades [6]. In order for successful global trade, the term "glocalisation" is suggested to think globally and act locally. Several cases of global manufacturing businesses could be employed in order to revolutionize and transform the traditional supply chain patters in an effective and sustainable manner. McDonald's would be a proper example for instance, whereas it offers both globally well-known products such as Coca-Cola and typical burgers, and also adopts the local viewpoint of offering the specific foods in order to satisfy the desires of local people [6]. A research study examined 
distribution system of John Lewis partnership [6]. In order to facilitate extra warehousing capacity, John Lewis expanded its distribution infrastructure while establishing a new semi-automated national distribution centre (SANDC) in 2013, to assemble products within the layout sequence and enhance efficiency.

SSCM is defined as "the strategic, transparent integration and achievement of an organization's social, environmental, and economic goals in the systemic coordination of key inter-organizational business processes for improving the long-term economic performance of the individual company and its supply chains" [7]. The application of SSCM implementation is fairly recent and still under-developed [8], and this could be due to the lack of comprehensive agenda towards effective SSCM [9]. Three main parameters are considered for sustainable logistics and SCM including reverse logistics, assessment of emissions and the greening of logistical activities and supply chains [10]. Extending the supply chain operations reference model (SCOR) developed by supply chain council (SCC), together with the sustainability factor on the top, the strategies for adoption of SSCM are well-defined [11]. The framework provides a proper foundation towards defining the most effective sustainable demand chain model in the future. Four significant approaches are identified including risk mitigation, cost minimisation, competitive advantage and supply chain transformation (Fig. 1).

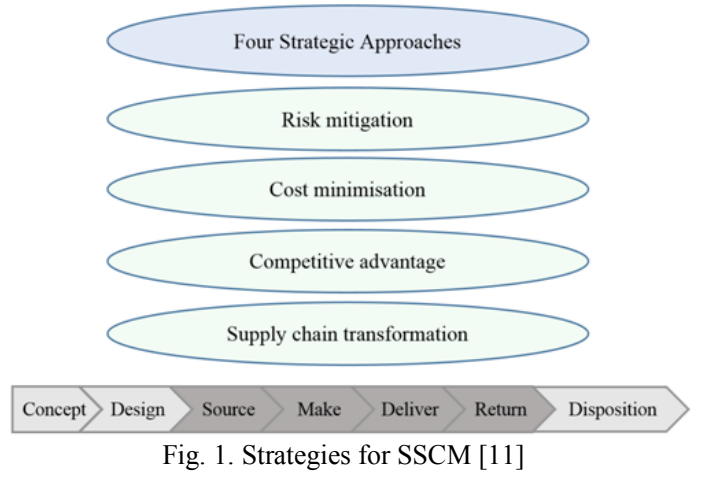

In order for better application of sustainability within industrial organisations, codes of conduct (ethical codes) have been defined comprising of four different parameters; labour practices, corporate governance, supplier practices, general morals and ethics. In order for the codes of conduct to be effective, the full commitment from top management would be necessary to apply supply chain performance measurements and metrics and also redefine the company vision and mission considering TBL [8]. In doing so, each firm needs to evaluate its sustainable initiatives with the aid of a specific technique such as environmental management system (EMS) and life cycle assessment (LCA). Apple Company as a world supply chain master [12] is currently conducting the supplier auditing scheme by sending Apple auditor to lead every on-site audit, supported by expert local third-party auditors who are trained for using the Apple's auditing protocols and codes of conduct [8].
Moreover, they perform some annual audits for their tier-1 suppliers and further audits for suppliers with certain risk levels [8].

\section{B. Sustainable Demand Chain as an Alternative}

Replacing the sustainable demand chain management (SDCM) with supply perspective, sustainability will be integrated into activities beyond the main supply chain concepts such as involving customers to management of by-products generated after home or industrial use and product life extension [13]. As a result, the demand-centric firm would be altered and enhanced from an isolated entity to a complex and dynamic one running by various resources, supply networks and markets. According to Fig. 2, a well-defined conceptual framework is presented for SDCM [14] that takes the customer perspective and transforms the traditional purchasing focused flow of supply chain while taking goals from the TBL of the business [15]. It is stated that the sustainable value performance is a concept that needs to be defined from the customer sustainability dimensions as an output rather than the suppliers' perspective that results in creation of sustainable value proposition [14]. The model starts with demand chain profiling and the information flow deriving from evaluation of business environments based on the TBL, analysis of market segments and consumption patterns.

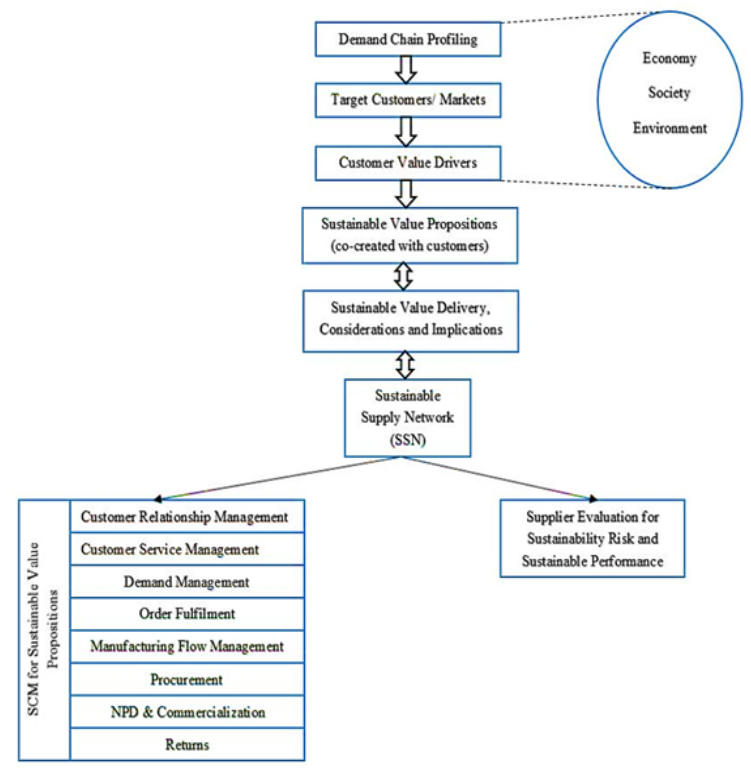

Fig. 2. A conceptual framework for SDCM [14]

These parameters would act as inputs for the creation of sustainable customer value propositions and finally lead to sustainable supply network (SSN) where the several entities of the supply chain utilize several resources in order to gain sustainability principles within a value chain instead of a radical single firm-centric approach exerting power on the suppliers in a linear and simplistic way. Besides, the model highlights an integration between 
purchasing and marketing entities at the sustainable value delivery stage [14].

\section{METHODOLOGY}

This research is based on both qualitative and quantitative data which is facilitated through detailed company surveys using office visit and questionnaire administration. After exploration of the most recent review of literature relevant to the field of study and the research gaps in knowledge within this area, a case study based method has been employed towards the purpose of this study in order to evaluate the manufacturing company strategies both from the sustainable supply and demand chain perspectives. There is a necessity in both academia and practice in order to move from supply chain towards demand driven chains due to the fact that still there is a gap especially in literature investigating the demand chain concepts considering sustainability dimensions. The proposed case study seeks to describe the characteristics of a sustainable supply and demand chain within a global manufacturing company based on the collected data from document research, industry association data based on the questionnaire conduction. Investigating the case and proper evaluation of the company within SSCM and SDCM context became possible with the aid of industrial experts in the manufacturing company and primary data.

\section{A. Company Overview}

This study has been conducted in collaboration within Company X, a global tyre manufacturing company as part of a holding company. Company X is established in 1993 as the largest non-governmental tyre manufacturer by market share with the preliminary production capacity of 5000 tons per year, which is now increased to 40,000 tons per year within more than 30 sizes of tyres including automobiles, commercial trucks, light trucks, sport utility vehicles (SUVs), race cars, airplanes, and heavy earthmover machinery. The company is currently operating as one of the largest tyre exporters while providing tyre supplies for the two largest automobile manufacturing companies in the country. The company goals and values are to be committed to quality, continuous learning and improvement, customer orientation, creativity considering talented manpower, confidence, honesty and obligation.

\section{B. Execution of the Study}

Based on the characteristics and main concepts of this study, the target population of the study would be consisting of those parties relevant to both supply and demand chain consisting of marketing and commercial departments within Company X.

The designed survey questionnaire is administrated to 10 members of the organization including commercial experts and marketing experts. Moreover, the marketing manager, the commercial manager, the $\mathrm{CEO}$ and the 2 shareholders provided with the opportunity for the questionnaire to be conducted. Hence, 15 participants were engaged in the survey in total. By doing so, their primary knowledge, current, accurate and factual data would provide the most appropriate results for the study purposes. As a result, the researcher will also draw assumptions and derive findings based on the existing information and perform the analysis in the higher steps.

The term SSDC is introduced to make a bridge between the purchasing and consuming viewpoints in order for a more inclusive study; according to the fact that both SSCM and SDCM approaches together lead to compelling unique value proposition. The main aim of the survey is to find out the commercial and marketing departments' level of knowledge towards the specified green supply and demand chain features. The survey questionnaire seeks to fulfil the following key objectives through conduction of the primary research within Company $\mathrm{X}$ :

(a) To understand the factors influencing company executives to move towards undertaking a SSDC approach;

(b) To identify the current status of SSDC practices within the company to find out the existing gaps and required actions;

(c) To explore the benefits and influence of SSDC implementation on company's overall performance.

The five-point Likert scale technique is used for the questionnaire design in order to record the ratings of the responses. The key Likert scale questions identified for the qualitative data collection is shown as Table 1 (Q1-Q4).

TABLE I

KEY RESEARCH SURVEY QUESTIONS

\begin{tabular}{|c|l|c|c|}
\hline $\begin{array}{c}\text { No } \\
.\end{array}$ & \multicolumn{1}{|c|}{ Question } & $\begin{array}{c}\text { Research } \\
\text { Objective }\end{array}$ & Reference \\
\hline 1 & $\begin{array}{l}\text { In which department are you } \\
\text { in? What is your task within } \\
\text { that department? }\end{array}$ & $\begin{array}{l}\text { From your perspective, based } \\
\text { on your experience working in a } \\
\text { global manufacturing } \\
\text { environment, how important are } \\
\text { the factors listed below in } \\
\text { influencing the implementation } \\
\text { of SSDC in your company? }\end{array}$ & (a) \\
\hline 3 & $\begin{array}{l}\text { What is the current stage of } \\
\text { SSDC implementation in your } \\
\text { company? }\end{array}$ & (b) & [14] [16] \\
\hline 4 & $\begin{array}{l}\text { How significant is the influence } \\
\text { of SSDC implementation on } \\
\text { your company's performance in } \\
\text { the area listed below? }\end{array}$ & (c) & [7] [8] [14] \\
\hline
\end{tabular}

\section{RESULTS AND DATA ANALYSIS}

It would be noted that Question 1 is only conducted in order to keep the records of the respondents. All the gathered data from Question 2, 3 and 4 conducted to 15 personnel of the Company $\mathrm{X}$ will be illustrated in the 
statistic charts and subsequently will be analysed in order to achieve integrated results towards the case discussions.

As it is evident from Fig.3, the cost of using ecofriendly materials, cost for disposal of hazardous wastes and industrial associations with professional organisations were ranked as the highest important influential factors towards implementation of SSDC with 67\%, 53.3\% and $40 \%$ respectively. These results would note the high costs involved and the premium price as one of the frequent issues regarding the green produces [17]. However, the high costs associated are due to the new concept of greening and the low market demand which are already being increased as a result of new marketing and advertising goals, improvement of people mind-sets towards getting more cultured regarding the benefits of such products. Besides, competitors' green strategy and government regulations \& financial support were ranked as the highest important influential factors towards implementation of SSDC with $53.3 \%$ and $46.6 \%$ respectively. On the contrary, customer demand and competitors' green strategy mainly mentioned as totally unimportant components by $33.3 \%$ and $20 \%$ with no pressure and little influence towards leading the company towards adoption of sustainable demand chain practices in particular. Considering the suppliers' advances in green technology, the respondents have recorded $40 \%$ neutral answers, which can be interpreted in different ways. First that the company is yet to set up partnerships with green suppliers, especially the tier ones. Secondly, there still might be a lack of R\&D and sustainability academic technical knowledge within the raw material suppliers of tyre manufacturing industry.

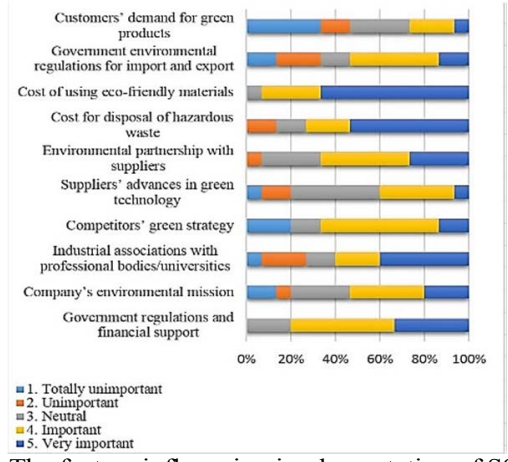

Fig. 3. Q2: The factors influencing implementation of SSDC in Company X.

Question 3 classifies the significant components of SSDC and the different levels that managers have yet considered to undertake the gradual successful implementation of them. According to Fig. 4 it would be surprising that among all the sustainable actions, the sales of scrap and used materials are already implemented successfully as ranked by $80 \%$ of the respondents. The use of green transportation vehicles and sales of excessive inventories are rated by $40 \%$ and $60 \%$ that are situated within the early steps of consideration. By contrast, design of green products, green cooperation with customers, commitment to SSCD from senior managers and supply chain transformation were judged as not to be fully considered and these need to be more focused.

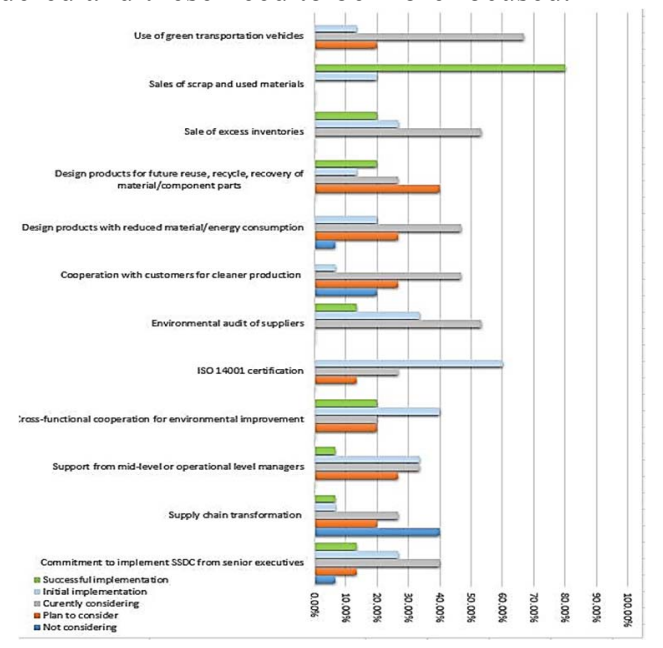

Fig. 4. Q3: The current status of SSDC implementation within Company $\mathrm{X}$.

Fig. 5 indicates that the top four factors affecting the overall performance of the company are including the reverse logistics (73.3\%), improved capacity/service utilisation $(66.6 \%)$, improved product quality $(60 \%)$ and improved investment improvement $(46.6 \%)$. This could prove the fact that the company executives observe the SSDC more through a financial perspective rather than an environmental vision, however, the reverse logistics is known as a vital factor enabling the supply chain logistics and SCM [10].

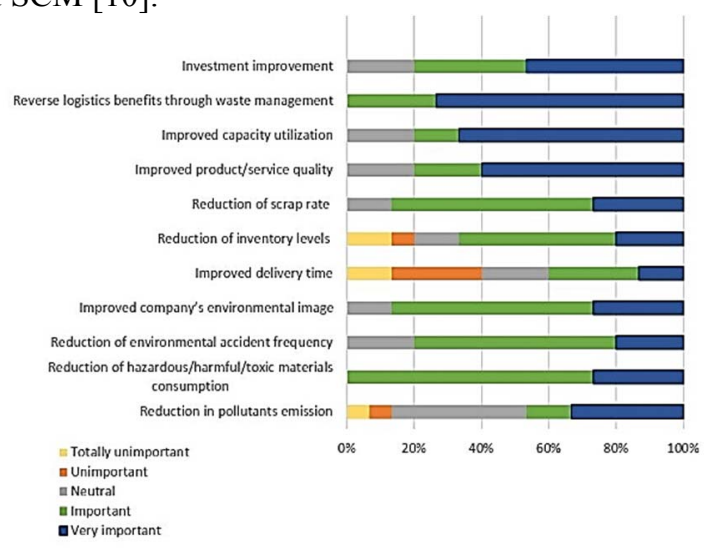

Fig. 5. Q4: The influence of SSDC within overall Company X performance.

\section{DISCUSSION}

The research results show that the three parameters of SSCM [10] including reverse logistics, assessment of emissions and the greening of logistical activities had an acceptable standard in the case company; however it requires extra consideration from the manufacturing and $\mathrm{R} \& \mathrm{D}$ engineers to communicate and get involved in risk mitigation SSCM and SDCM approaches. Besides, the application of codes of conduct could be exploited 
particularly within the selection of suppliers through LCA and EMS metrics for instance [8]. The efficiency of such green programs in any company would be merely possible through the proficiency of company project leaders and task force teams (TFTs) and their collaboration with professional academia along with financial and motivational aids of a supportive government. Moreover, moving towards SSDC approaches, the supply chain logistic patterns could be transformed through the collaboration of different functions of the holding company or even the other tyre manufacturing industries within the country. However, the main finding of the study is that there is an urgent need for the world governments to make closer ties and integrations towards motivating, convincing and supporting diverse global stakeholders in order to make investments and define strategic plans towards adoption of environmental sustainability and transform their supply chain models to achieve the benefits of SSDC as a result. Furthermore, the positive point is that there is an increasing rate of greening knowledge and SSCM practices in the current industry generation which could be gradually cultivated to reach the point that all the global stakeholders become committed and responsible of such practices.

\section{CONCLUSION}

Several novel frameworks of SSCM and SDCM concepts have already been developed within world literature and a nutshell is investigated in this paper. Earlier researches indicated the conceptual frameworks of SSCM and SDCM strategies and the benefits of adoption of each as an individual concept. This paper presents a wellgrounded basis for future research utilising a case study approach as a real model of how and to what extent the global manufactures could positively impact on the environmental challenges and what the scarcities are within the context of SSDC concept especially in developing countries which still lack the proper foundations and broad visions. Therefore, a key future research area is to explore how the global stakeholders could be involved to achieve the best advantages out of the combined SSDC frameworks. Moreover, it is essential to establish stronger empirical frameworks in order to find out the interactions between SSCM and SDCM as new emerging concepts within industrial environments.

\section{ACKNOWLEDGMENT}

This research team would like to acknowledge the Department of Applied Engineering Management and the research is supported by the Faculty of Engineering and Science, University of Greenwich UK, under the VCScholarship programme 2016.

\section{REFERENCES}

[1] T. Friscia, K. O’Marah, D. Hofman, and J. Souza, "The AMR Research Supply Chain Top 25 for 2009," [Online] Boston: AMR Research. Available at: $<$ www.sdn.sap.com/irj/scn/go/portal/prtroot/docs/library/u uid/0043dfd9-1440-2c10-0887-

d72ab37b8fca?QuickLink=index\&overridelayout $=$ true \&4 3770011733719> [Accessed 1 May 2017], 2009.

[2] S. Emmett, and B. Crocker, The relationship-driven supply chain creating a culture of collaboration throughout the chain, Aldershot, England: Gower Publishing, 2006.

[3] M. Rainbird, "Demand and supply chains: the value catalyst," International Journal of Physical Distribution \& Logistics Management, vol. 34, no. 3/4, pp. 230-250, 2004.

[4] A. Fuad-Luke, The eco-design handbook: A complete sourcebook for the home and office. $3^{\text {rd }}$ ed. London: Thames \& Hudson, 2009.

[5] S. Walker, Sustainable by design: Explorations in theory and practice, London: Earthscan Publications, 2006.

[6] J. Mangan, C. Lalwani, T. Butcher, and R. Javadpour, Global Logistics and Supply Chain Management. $2^{\text {nd }}$ ed. John Wiley \& Sons, 2012.

[7] C.R. Carter, and D.S. Rogers, "A framework of sustainable supply chain management: moving toward new theory," International Journal of Physical Distribution \& Logistics Management, vol. 38, no. 5, pp. 360-387, 2008.

[8] D.B. Grant, A. Trautrims, and C.Y. Wong, Sustainable Logistics and Supply Chain Management (Revised Edition). Kogan Page Publishers, 2015.

[9] S. Brockhaus, W. Kersten, and A. M. Knemeyer, "Where Do We Go From Here? Progressing Sustainability Implementation Efforts across Supply Chains," Journal of Business Logistics, vol. 34, no. 2, pp. 167-182, 2013.

[10] S.M. Abukhader, and G. Jönson, "Logistics and the environment: Is it an established subject?," International Journal of Logistics Research and Applications, vol. 7, no. 2, pp.137-149, 2004.

[11] M. Bernon, "Sustainable supply chain management," in The Business \& Management Collection, [Online] Henry Stewart Talks Ltd, London. Available at: $<$ hstalks.com/bm/1872/> [Accessed 10 May 2017], 2010.

[12] S. Aronow, M. Burkett, K. Nilles, and J. Romano, "The Gartner Supply Chain top 25 for 2016," Gartner Inc. [Online] Available at: $<$ www.gartner.com/doc/3321523?ref=SiteSearch\&sthkw= top\%20supply\%20chain $\% 202016 \&$ fnl=search\&srcId $=1$ 3478922254> [Accessed 12 May 2017], 2016.

[13] J.D. Linton, R. Klassen, and V. Jayaraman, "Sustainable supply chains: An introduction," Journal of operations management, vol. 25, no. 6, pp.1075-1082, 2007.

[14] C.A. Vural, "Sustainable demand chain management: An alternative perspective for sustainability in the supply chain," Procedia - Social and Behavioral Sciences, vol. 207, pp. 262-273, 2015.

[15] T.E. Vollmann, and C. Cordon, "Building successful customer-Supplier alliances," Long Range Planning, vol. 31, no. 5, pp.684-694, 1998.

[16] A. McKinnon, M. Browne, A. Whiteing, Green logistics: Improving the environmental sustainability of logistics. $2^{\text {nd }}$ ed. Kogan Page Publishers, 2012.

[17] R. Drozdenko, M. Jensen, and D. Coelho, "Pricing of green products: Premiums paid, consumer characteristics and incentives," International Journal of Business, Marketing, and Decision Sciences, vol. 4, no. 1, pp.106-116, 2011. 